\title{
Article \\ Colonization and Authentication of the Pyrethroid-Resistant Anopheles gambiae s.s. Muleba-Kis Strain; an Important Test System for Laboratory Screening of New Insecticides
}

\author{
Salum Azizi 1,2,*, Janneke Snetselaar 1,2,3,4, Alexandra Wright ${ }^{4}$, Johnson Matowo 1,2, Boniface Shirima 1,2, \\ Robert Kaaya ${ }^{1,2}$, Rashid Athumani ${ }^{1,2}$, Filemoni Tenu ${ }^{1,2}$, Natacha Protopopoff 1,2,4 and Matthew Kirby ${ }^{1,2,4}$
}

1 Department of Medical Parasitology and Entomology, Kilimanjaro Christian Medical University College, Moshi 255, Tanzania; janneke.snetselaar@lshtm.ac.uk (J.S.); johnson.matowo@pamverc.or.tz (J.M.); boniface.shirima@pamverc.or.tz (B.S.); robert.kaaya@pamverc.or.tz (R.K.); rashid.athumani@pamverc.or.tz (R.A.); filemoni.tenu@pamverc.or.tz (F.T.); Natacha.Protopopoff@lshtm.ac.uk (N.P.); matthew.kirby@lshtm.ac.uk (M.K.)

2 Pan African Malaria Vector Research Consortium, Moshi 255, Tanzania

3 The Innovative Vector Control Consortium, Liverpool L3 5QA, UK

4 Department of Disease Control, London School of Hygiene and Tropical Medicine, London WC1E 7HT, UK; Lauren.wright@lshtm.ac.uk

* Correspondence: salum.azizi@pamverc.or.tz; Tel.: +255-692804666

Citation: Azizi, S.; Snetselaar, J.; Wright, A.; Matowo, J.; Shirima, B.; Kaaya, R.; Athumani, R.; Tenu, F.; Protopopoff, N.; Kirby, M. Colonization and Authentication of the Pyrethroid-Resistant Anopheles gambiae s.s. Muleba-Kis Strain; an Important Test System for Laboratory Screening of New Insecticides. Insects 2021, 12, 710. https://doi.org/ $10.3390 /$ insects 12080710

Academic Editor: Rosemary S. Lees

Received: 20 May 2021

Accepted: 19 July 2021

Published: 8 August 2021

Publisher's Note: MDPI stays neutral with regard to jurisdictional claims in published maps and institutional affiliations.

Copyright: (c) 2021 by the authors. Licensee MDPI, Basel, Switzerland. This article is an open access article distributed under the terms and conditions of the Creative Commons Attribution (CC BY) license (https:// creativecommons.org/licenses/by/ $4.0 /)$.
Simple Summary: Malaria control and prevention have traditionally relied on the use of insecticides in the form of treated bed nets or residual spraying in households. However, scaling up of these interventions-based on few available insecticide classes-resulted in the development and spread of insecticide resistance in malaria-transmitting mosquitoes. There is therefore an urgent need for introducing and applying new insecticides that are effective against these mosquitoes. Laboratories tasked with evaluating the efficacy of novel insecticides need to establish a large colony of resistant mosquitoes. In this study, we report the procedures used and challenges faced during the establishment and maintenance of a resistant mosquito strain in the laboratory which reflects the characteristics of the wild-resistant mosquito populations found in East Africa.

Abstract: Background: The emergence and spread of insecticide resistance in malaria vectors to major classes of insecticides call for urgent innovation and application of insecticides with novel modes of action. When evaluating new insecticides for public health, potential candidates need to be screened against both susceptible and resistant mosquitoes to determine efficacy and to identify potential cross-resistance to insecticides currently used for mosquito control. The challenges and lessons learned from establishing, maintaining, and authenticating the pyrethroid-resistant An. gambiae s.s. Muleba-Kis strain at the KCMUCo-PAMVERC Test Facility are described in this paper. Methods: Male mosquitoes from the $\mathrm{F}_{1}$ generation of wild-pyrethroid resistant mosquitoes were cross-bred with susceptible female An. gambiae s.s. Kisumu laboratory strain followed by larval selection using a pyrethroid insecticide solution. Periodic screening for phenotypic and genotypic resistance was done. WHO susceptibility tests and bottle bioassays were used to assess the phenotypic resistance, while Taqman ${ }^{\mathrm{TM}}$ assays were used to screen for known target-site resistance alleles $(k d r$ and ace1). Additionally, the strains were periodically assessed for quality control by monitoring adult weight and wing length. Results: By out-crossing the wild mosquitoes with an established lab strain, a successful resistant insectary colony was established. Intermittent selection pressure using alphacypermethrin has maintained high $k d r$ mutation (leucine-serine) frequencies in the selected colony. There was consistency in the wing length and weight measurements from the year 2016 to 2020 , with the exception that one out of four years was significantly different. Mean annual wing length varied between $0.0142-0.0028 \mathrm{~mm}$ compared to values obtained in 2016, except in 2019 where it varied by $0.0901 \mathrm{~mm}$. Weight only varied by approximately $0.001 \mathrm{~g}$ across four years, except in 2017 where it differed by $0.005 \mathrm{~g}$. Routine phenotypic characterization on Muleba-Kis against pyrethroids using the WHO susceptibility test indicated high susceptibility when type I pyrethroids were used compared to type II pyrethroids. Dynamics on susceptibility status also depended on the 
lapse time when the selection was last done. Conclusions: This study described the procedure for introducing, colonizing, and maintaining a resistant An. gambiae s.s. strain in the laboratory with leucine to serine substitution $k d r$ allele which reflects the features of the wild-resistant population in East Africa. Challenges in colonizing a wild-resistant mosquito strain were overcome by out-crossing between mosquito strains of desired traits followed by intermittent insecticide selection at the larval stage to select for the resistant phenotype.

Keywords: insecticide selection; out-crossing; strain authentication; laboratory screening

\section{Introduction}

Malaria vector control principally relies on the use of Insecticidal Treated Nets (ITNs) and Indoor Residual Spraying (IRS) as the most effective measures to prevent malaria transmission [1]. Historically, pyrethroids were used extensively for conventionally treated nets, superseded by Long Lasting Insecticidal Nets (LLINs), and also used for IRS due to their efficacy, relatively long persistence compared to other insecticides [2-4], and perceived low toxicity to humans [5-8]. However, the development and spread of pyrethroid resistance in malaria vector populations [4,9] demanded the development of new classes of insecticides with novel modes of action (MoA) for the control of mosquitoes and other disease vectors [10-13].

In developing new insecticides, several stakeholders are required in the process. The Innovative Vector Control Consortium (IVCC) has pioneered the bonding of prime agrochemical innovator industries, with research and academic institutions as key stakeholders in developing and evaluating new insecticides for mosquito control to prevent malaria and other neglected tropical diseases [14]. Research institutions perform laboratory and field screening of new chemistries for efficacy against mosquito populations and identify any cross-resistance risks at an early stage in the product development pipeline [15]; in this process mosquitoes are required as test systems [15,16]. In response to the global escalation of insecticide resistance in mosquito vectors, the WHO specifically recommends the establishment, authentication, and use of resistant mosquito strains during phase I efficacy testing of new non-pyrethroid insecticides [16]. This recommendation ensures that the evaluation will be able to capture efficacy against current resistance in malaria vectors. Authentication of a new insectary strain involves routine confirmation of the unique characteristics of the strain that sufficiently distinguish it from all others held in the same facility. This comprises routine validation of the species or subspecies identity, plus the resistance status as defined by genotypic and/or phenotypic characteristics $[17,18]$. In establishing a resistant insectary colony under artificial rearing conditions, the field sourced mosquitoes undergo several bottlenecks that could impair its suitability for the tests. Due to lack of variation and complexity in artificial rearing conditions, adaptation to these settings can favor populations to evolve in new directions from wild populations, especially when selection pressures and nutrition differ between the two settings $[19,20]$. Laboratory maintenance of insects in discrete generations facilitates selection for individuals that reproduce early and develop faster [21,22]. It is reported that adaptation to artificial environment can result in significant rapid evolutionary traits changing compared to natural populations $[23,24]$. This can lead to problems when reared insects are intended for release as biocontrol agents or in sterile insect control programs, when using laboratory strains to comprehend field population dynamics, and when using reared strains to predict vector control tools' effectiveness in the field. Attempts have been made to minimize the genetic drift and inbreeding effects through crossing an established laboratory stock with outbred field stock $[25,26]$. However, there is less utility for crossing the laboratory strain with field mosquitoes to maintain a complete genetic background of field populations when the colony is established to serve as a close representative for a few defined traits 
which can be fixed, and when the ultimate use is limited to laboratory and semi-field environments.

In 2008, the Insecticide Testing Facility (ITF) of the Kilimanjaro Christian Medical University College-Pan-African Malaria Vector Research Consortium (KCMUCo-PAMVERC) Test Facility in Moshi Tanzania was initiated in parallel with a molecular laboratory, two insectaries, and three field stations. In the insectaries, the Test Facility established Aedes, Anopheles, and Culex mosquito colonies of different insecticide resistance profiles. From 2008-2011, Anopheles mosquitoes kept at the KCMUCo-PAMVERC Test Facility were limited to susceptible An. gambiae sensu stricto Kisumu (susceptible to all classes of insecticides used for vector control) and An. arabiensis collected from lower Moshi and reared to first filial generation (F1), the pyrethroid-resistant vector local to the Test Facility $[27,28]$. In 2012, the Test Facility acted to establish a colony of pyrethroid-resistant An. gambiae s.s. that would represent a typical East African resistant population. The An. gambiae Muleba-Kis strain was established and has been maintained in the insectary for years and propagated over hundreds of generations successfully, a feature emphasized by some scientists to qualify a colony as a strain [29]. The established An. gambiae Muleba-Kis strain is similar to East African An. gambiae s.s. populations for having the East African knockdown resistance (L1014S), a sodium channel mutation in An. gambiae that confers DDT and pyrethroid resistance [30]. The origin of L1014S mutation is Eastern Africa [30,31], hence the name $k d r$-east, although currently this mutation is no longer geographically restricted to East Africa $[32,33]$ and its occurrence is frequently associated with the West African mutation L1014F $[33,34]$. Different types of pyrethoids, namely type I and type II, affect mosquitoes with $k d r$ (East or West or mixture) differently. Pyrethroids are classified based on their chemical structures; type I pyrethroids lack the cyano-moiety present at the $\alpha$ position of type II pyrethroids. The type II pyrethroids generally delay the inactivation of the voltagegated sodium channel substantially longer, and their effects are less reversible than type I pyrethroids [35]. Due to the similar steric profile with pyrethroids, DDT, an organochlorine, is affected with resistance to pyrethroids which often provides cross-resistance to DDT. A study by Reimer reported that mosquito populations carrying a high $k d r$ frequency showed more resistance to DDT and type I pyrethroids than to type II pyrethroids [36].

The L1014S mutation has been fixed in a population of An. gambiae s.s. in Muleba District, north-western Tanzania [37,38], Busia, and Mayuge Districts in Eastern Uganda [39]. The occurrence of the L1014S mutation but at lower frequencies has been reported elsewhere in Tanzania [40], Kenya [41], and Uganda [42,43]. In previous studies done in Muleba district, where mosquitoes for this study were collected, it has also been reported that mosquitoes are resistant to bendiocarb, DDT, permethrin and deltamethrin, although there was no evidence for Ace-1 mutation [37]. Another study, a national-wide survey for resistance [44], reported $A n$. gambiae s.l. resistance to pirimiphos-methyl for the first time in three sites (including Muleba district) out of 20 sites in Tanzania. Since the target site to organophosphates and carbamates is the AChE enzyme and that resistance in mosquitoes to this target site is frequently a G119S mutation in the ace-1 gene [45], it is therefore reasonable to characterize L1014S and Ace-1 mutations as desired traits in the established colony to resemble the parental resistant population.

In this paper, we describe the procedures undertaken at the KCMUCo-PAMVERC Test Facility to establish a pyrethroid-resistant strain called An. gambiae s.s. Muleba-Kis. Here we focus on the procedures and lessons learned from out-crossing, artificial resistance selection, bioassays, and genotyping assays used to authenticate this strain for over two hundred generations. We describe data on the stability of resistance traits and fitness parameters over eight years. These data provide baseline resistance information on the outcome of the long-term intermittent selection of mosquito larvae. 


\section{Materials and Methods}

\subsection{Study Site}

From April to May 2012, An. gambiae s.l. mosquitoes were collected in houses in two villages: Kyamyorwa $\left(02^{\circ} 04^{\prime} 27.5^{\prime \prime} \mathrm{S}, 31^{\circ} 34^{\prime} 10.8^{\prime \prime} \mathrm{E}\right)$ and Kiteme $\left(02^{\circ} 03^{\prime} 20.9^{\prime \prime} \mathrm{S}\right.$, $31^{\circ} 27^{\prime} 16.8^{\prime \prime} \mathrm{E}$ ) in Muleba, a rural district on the western shore of Lake Victoria in northwest Tanzania (Figure 1).

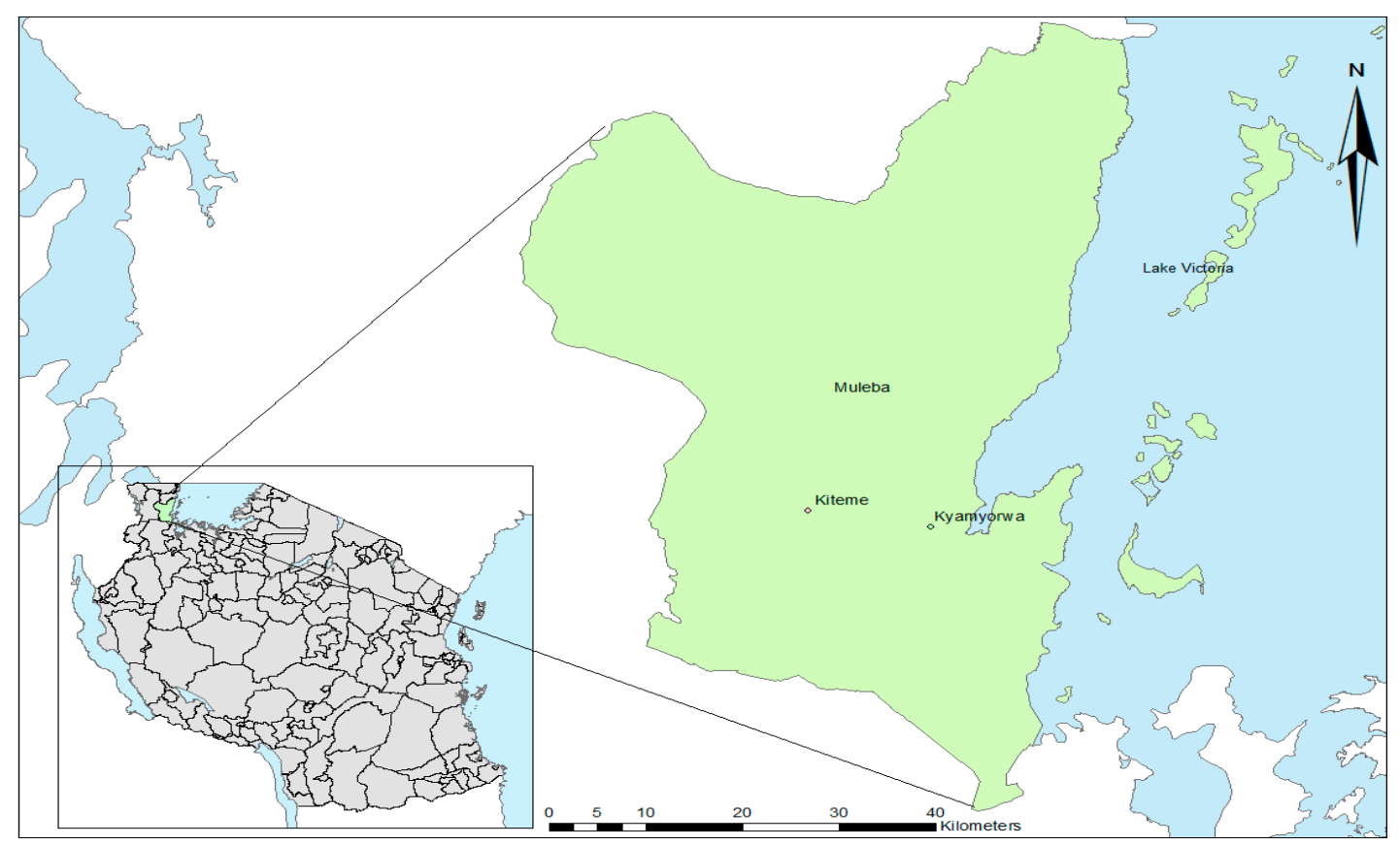

Figure 1. Map showing mosquito collection site in north-western Tanzania.

The mosquito collection for this study was part of an ongoing large cluster randomized trial in Muleba district, north-western Tanzania [46]. An. gambiae s.s. were the main vectors found in this area and have historically exhibited high resistance levels to pyrethroids [28], with mortality after exposure not exceeding 35\%. The L1014S point mutation associated with pyrethroid resistance was nearly fixed, while no Ace-1 mutation was found [37].

\subsection{Timeline}

The timeline below, Figure 2, indicates the sequence of activities in this study across generations of An. gambiae Muleba-Kis.

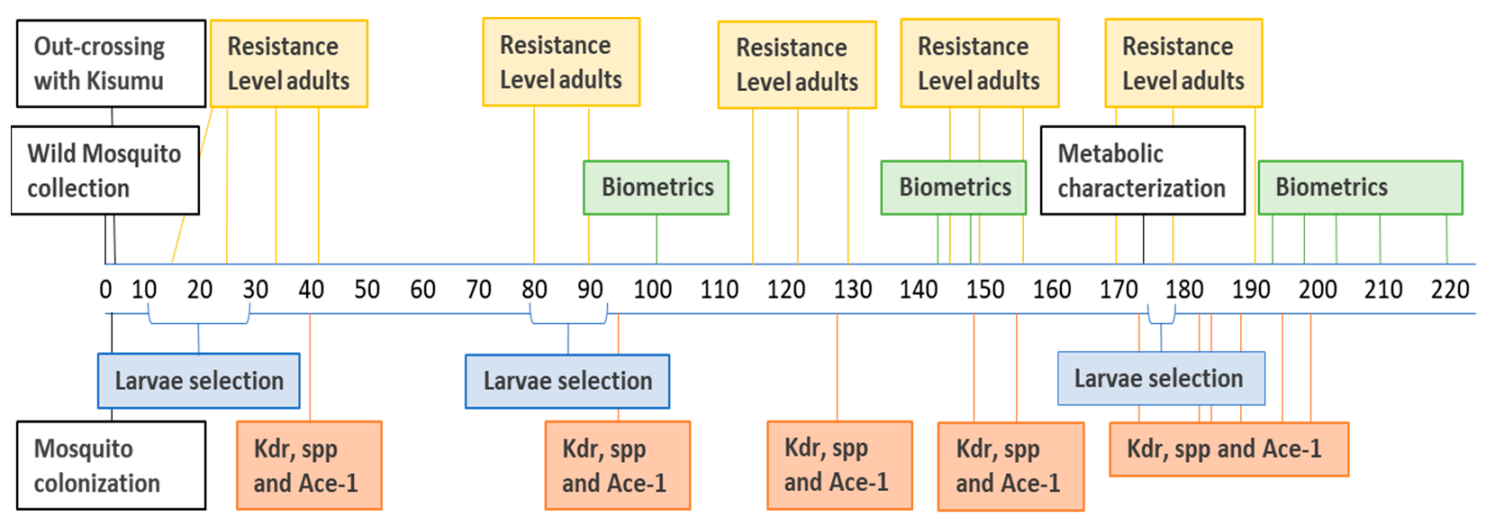

Figure 2. The timeline for activities, indicating wild mosquito collection, insectary colonization, out-crossing, selection, and strain characterization across An. gambiae Muleba-Kis generations. 


\subsection{Collection of Wild Mosquitoes and Introduction into the Insectary}

Indoor resting blood-fed Anopheles were collected in house bedrooms using mouth aspirators. Mosquitoes were transferred in paper cups supplemented with glucose and transported to field insectaries located in Muleba. They were held under ambient relative humidity and temperature conditions in $30 \times 30 \times 30$ mosquito cages containing a petri dish of moistened cotton wool overlaid with damp filter paper for egg laying. After laying, adult $A n$. gambiae s.l. were stored individually and subsequently identified by Polymerase Chain Reaction (PCR) [47]. Collections were done over two months and eggs (approximately 500 eggs) were sent to the KCMUCo-PAMVERC Test Facility. Eggs were introduced into plastic bowls (6 L capacity) filled with $4 \mathrm{~L}$ of water. Larvae were reared under ambient temperature and relative humidity and fed with cereal for infants (Cerelac ${ }^{\circledR}$, Nestlé Kenya Limited, Pate, Kenya) mixed with ground sardines at a 2:1 ratio. Adult mosquitoes were reared at $60-90 \% \mathrm{RH}$ and $20-35^{\circ} \mathrm{C}$ in cages $(30 \mathrm{~cm} \times 30 \mathrm{~cm} \times 30 \mathrm{~cm})$ covered with untreated netting material and provided with glucose solution $10 \%$. To ensure optimal rearing conditions, insectary larval density was restricted to 200-300 per bowl ( $3 \mathrm{~L}$ capacity), water for mosquito rearing was pre-boiled to avoid bacterial infections, and environmental conditions (water and air temperature, relative humidity) were monitored and maintained.

\subsection{Crossing for "Insectary Vigor"}

When F1 mosquitoes were five days old, a restrained guinea pig was introduced into the cages of mosquitoes that were starved for one hour prior to blood-feeding. To overcome difficulties of adaptation to insectary conditions, out-crossing between female An. gambiae Kisumu and male An. gambiae Muleba mosquitoes were conducted. The main difficulties encountered were low blood-feeding, egg-laying, and survival, otherwise known as "insectary vigor." The An. gambiae Kisumu strain was obtained in 2008 through BEI Resources, NIAID, NIH: Anopheles gambiae, Strain KISUMU1, Eggs, MRA-762, contributed by Vincent Corbel. This strain is originating from Kisumu, Kenya, and was successfully established at our insectary and feeds well on guinea pigs. The Muleba and Kisumu strain pupae were collected separately, and males were separated from females on the first day after emerging. Adult male Muleba and female Kisumu mosquitoes were mixed at a ratio of $50: 50$ in a mosquito cage. These were reared at $20-35^{\circ} \mathrm{C}, 60-90 \% \mathrm{RH}$, and a natural $12: 12$ $\mathrm{h}$ L:D photoperiod, and were provided with a guinea pig for blood-feeding and filter paper medium for egg-laying. This successful outcrossed mosquito was then named " $A n$. gambiae s.s. Muleba-Kis strain" and has been reared at the KCMUCo-PAMVERC test facility since 2013.

\subsection{Selection to Maintain Pyrethroid Resistance}

In this study, selection was based on the exposure of larval mosquitoes to pyrethroid insecticides, and pyrethroids were chosen due to intensive usage in public health and having the most widespread resistance among mosquito vectors across Africa [48,49]. Artificial selection for pyrethroid resistance was started in the 15th generation. Six bowls each with around 100 larvae of 3rd to 4th instars were used initially, adopting a modified method by Shidrawi [50]. One $\mathrm{mL}$ of insecticide solution was added to $1 \mathrm{~L}$ of tap water at $27-32{ }^{\circ} \mathrm{C}$, stirred for $1 \mathrm{~min}$ using a Pasteur pipette, and then left for $10 \mathrm{~min}$ to allow evaporation of acetone which was used as a solvent for insecticide solution preparation. Larvae were transferred into the glass bowl with the dissolved insecticide solution, each bowl with around 100 larvae. A small amount of larvae food was added and larvae were left for $24 \mathrm{~h}$ in the selection bowl. After $24 \mathrm{~h}$, mortality was estimated. Mortality was estimated in three categories: high mortality, $67-100 \%$; moderate mortality, $34-66 \%$; or low mortality, $0-33 \%$. The initial selection was done using permethrin, and later alphacypermethrin was used for colony selection. The initial permethrin concentration used for the section was $0.1 \mathrm{mg} / \mathrm{L}$ and increased to $0.2 \mathrm{mg} / \mathrm{L}$ at a time when larvae mortality was in a low category. The initial alphacypermethrin concentration was $0.025 \mathrm{mg} / \mathrm{L}$ and it increased to 
$0.05 \mathrm{mg} / \mathrm{L}$ when larvae mortality was in a low category. The larvae were sieved when still alive from the selection bowl, rinsed with $500 \mathrm{~mL}$ water (temp $27-32{ }^{\circ} \mathrm{C}$ ) and returned to their original six bowls, and reared, while the dead larvae were removed. The selection was conducted intermittently. The availability of technical grade insecticide to make up the selection solutions and a need for mosquitoes for ongoing laboratory bioassays were the main constraints preventing routine artificial section of the colony.

\subsection{Authentication of the Outcrossed An. Gambiae s.s. Muleba-Kis Strain \\ 2.6.1. Phenotypic Resistance \\ WHO Susceptibility Test and CDC Bioassay}

Insecticide susceptibility bioassays were done from the 17th to 196th generation, in accordance with WHO guidelines [51]. Bioassays were carried out using six insecticides, namely permethrin $(0.75 \%)$, alphacypermethrin $(0.05 \%)$, deltamethrin $(0.05 \%)$, DDT $(4 \%)$, bendiocarb $(0.1 \%)$, and pirimiphos-methyl $(0.25 \%)$, and tests were conducted at $25 \pm 2{ }^{\circ} \mathrm{C}$ and $80 \pm 10 \%$ relative humidity. Each type of insecticide bioassay was performed in 5 replicates, including one as a control. Twenty to 25 , two-to-five-day-old female, blood unfed mosquitoes were tested, constituting a sample size of 100 to 125 mosquitoes for each insecticide. Tested mosquitoes were monitored for knockdown at 60 min and mortality at $24 \mathrm{~h}$ post exposure. In parallel with permethrin papers, limited WHO susceptibility bioassays were also conducted against bendiocarb papers $(0.1 \%)$ and pirimiphos-methyl $(0.25 \%)$. The insecticide resistance of the selected colony at the 190th generation was compared to the susceptible Kisumu strain using $\alpha$-cypermethrin in CDC bottle bioassay [52] at concentrations of 52.5, 25.7, 12.5, 6.1, 3, 1.5, and $0 \mu \mathrm{g}$ /bottle, where $12.5 \mu \mathrm{g} /$ bottle acted as a discriminating concentration for Anopheles [51].

\section{Synergist-Insecticide Bottle Bioassay}

In a separate experiment (unpublished) in 2018, at the 143rd generation, a synergist assay with piperonyl butoxide (PBO) was undertaken to assess the role of elevated mixedfunction oxidases in resistance. One hundred, 2-5-day-old female An. gambiae Muleba-Kis mosquitoes were tested for metabolic resistance using Piperonyl butoxide (PBO) in four replicates (25 mosquitoes per bottle) at a concentration of $100 \mu \mathrm{g} / \mathrm{mL}$ for one hour preexposure and then followed by $30 \mathrm{~min}$ exposure to permethrin $(21.5 \mu \mathrm{g} / \mathrm{mL})$, in accordance to the CDC guidelines [52], with the exception that mortality was considered at $24 \mathrm{~h}$ post-exposure. In brief, mosquitoes were pre-exposed to either acetone-coated bottles or PBO for $1 \mathrm{~h}$ at a temperature and humidity of $27 \pm 2{ }^{\circ} \mathrm{C}$ and $70 \pm 10 \% \mathrm{RH}$, respectively, during and after exposure. After pre-exposure, mosquitoes were transferred to holding cages for $60 \mathrm{~min}$ before being exposed for $30 \mathrm{~min}$ to bottles coated with either $21.5 \mu \mathrm{g} / \mathrm{mL}$ of permethrin or acetone as a control. After exposure, the mosquitos were transferred into holding cups and provided with $10 \%$ glucose-soaked cotton pads. After 60 min, post-exposure knockdown was recorded, and mortality was recorded $24 \mathrm{~h}$ post-exposure.

\subsubsection{Genotypic Basis of Resistance}

Detection of $k d r$ and Ace-1 Mutations

The frequency of leucine to serine mutations (L1014S), termed $k d r$ east ( $k d r$-e) and ace-1, were assessed and frequently monitored using the method described by Bass et al. [47,53] to monitor progress in resistance development after successive insecticide selection events. For Ace-1 and/or $k d r$-e alleles, a total of 84-88 samples were analyzed by PCR per each test.

\subsubsection{Species Identification and Biometric Measures for Fitness} Species Identification

To ensure colony species purity, at 43, 99, 131, 150, 162, 168, 178, 188, 190, 198, and 204th generations, the PCR for species identification was conducted using single nucleotide polymorphism genotyping [47]. At each generation, a total of 84-88 mosquito samples were tested. 


\section{Biometric Measurements}

The size of individual adult females was estimated by the average length of left wings, while weight was measured by weighing the whole mosquito. To measure the wing length, a total of one hundred Muleba-Kisumu females were randomly sampled from five selected mosquito-rearing cages quarterly, covering the 99th to 204th mosquito generations. The wings were cut and placed on a stage micrometer $(10 \mathrm{~mm}$ long with $100 \times 0.1 \mathrm{~mm}(100 \mu \mathrm{m})$ divisions). Wing length was measured as the distance from the alula to the end of the wing where vein three ends [54-56] using an ocular micrometer at $2 X$ objective magnification on a Nikon stereomicroscope, Model; SMZ 645 [Nikon Instruments, 1300 Walt Whitman Road, Melville, NY 11747-3064, U.S.A.], see Figure 3 below.

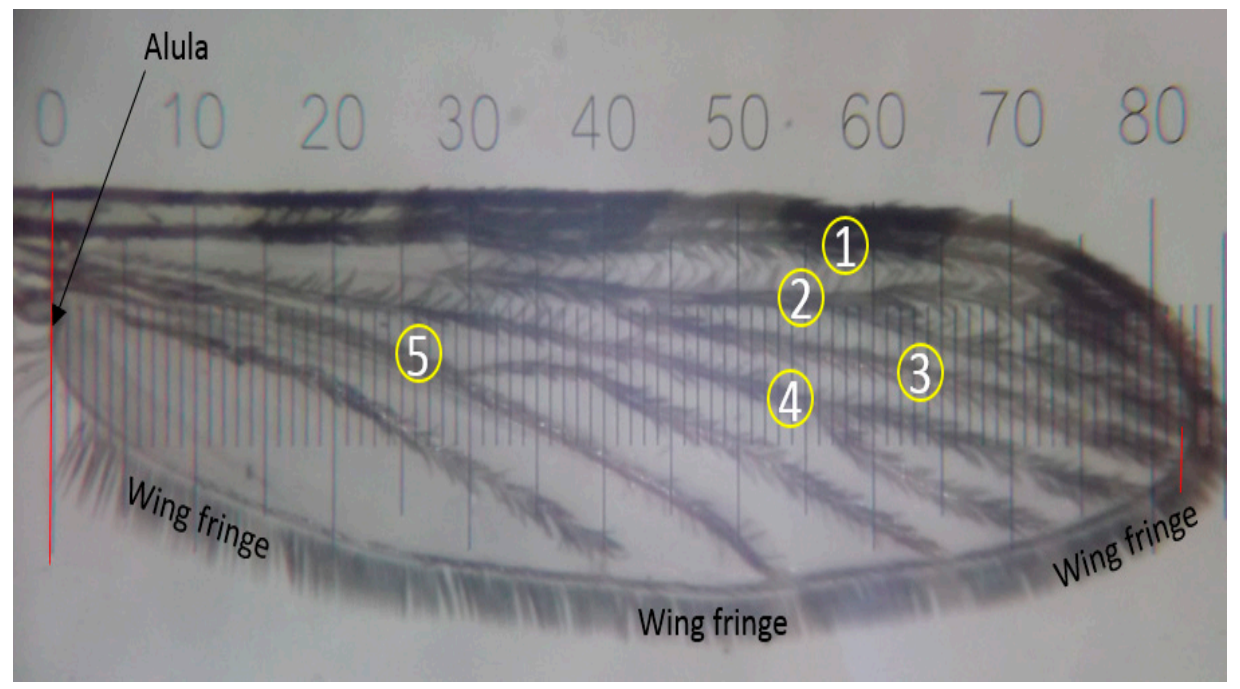

Figure 3. Image of wing aligned on a micrometer indicating the ocular gradations which correspond to the distance on the stage micrometer. Number 1-5 indicates the wing veins, where vein 3 is used for measuring the distance from the alula to the wing fringe (wing length). This photo was copied from PAMVERC Test Facility SOP with permission, originally taken and donated by MK (co-author).

Wing length and weight were continuously monitored in succeeding years regardless of whether selection with insecticide selection was done or not.

\subsection{Statistical Analysis}

The WHO criteria were used to classify the resistance or susceptibility status of the tested mosquito populations [51]. Descriptive analysis was performed to check for normality on wing and weight measures from the samples. Wing length and mosquito weight measures were all normally distributed. Using Stata [57], two sample T-tests were performed to compare wing length or mosquito weight across the years for the An. gambiae Muleba-Kisumu, and differences in mortality between An. gambiae Kisumu and An. gambiae Muleba-Kisumu across different concentrations in the CDC bottle bioassay.

\section{Results}

\subsection{Colony Selection}

Progressive selection with permethrin from the 15th to 29th generations for MulebaKisumu strain caused a drastic drop in susceptibility, indicated by the decrease in mortality (Figure 4). Inexplicably, although the same insecticide type and concentration was used for selection, susceptibility increased from the 30th generation to 35 th generation. From the 35th generation, selection was performed using alphacypermethrin. However, the selection with alphacypermethrin was not associated with an abrupt decrease of susceptibility, as selection was infrequent. 


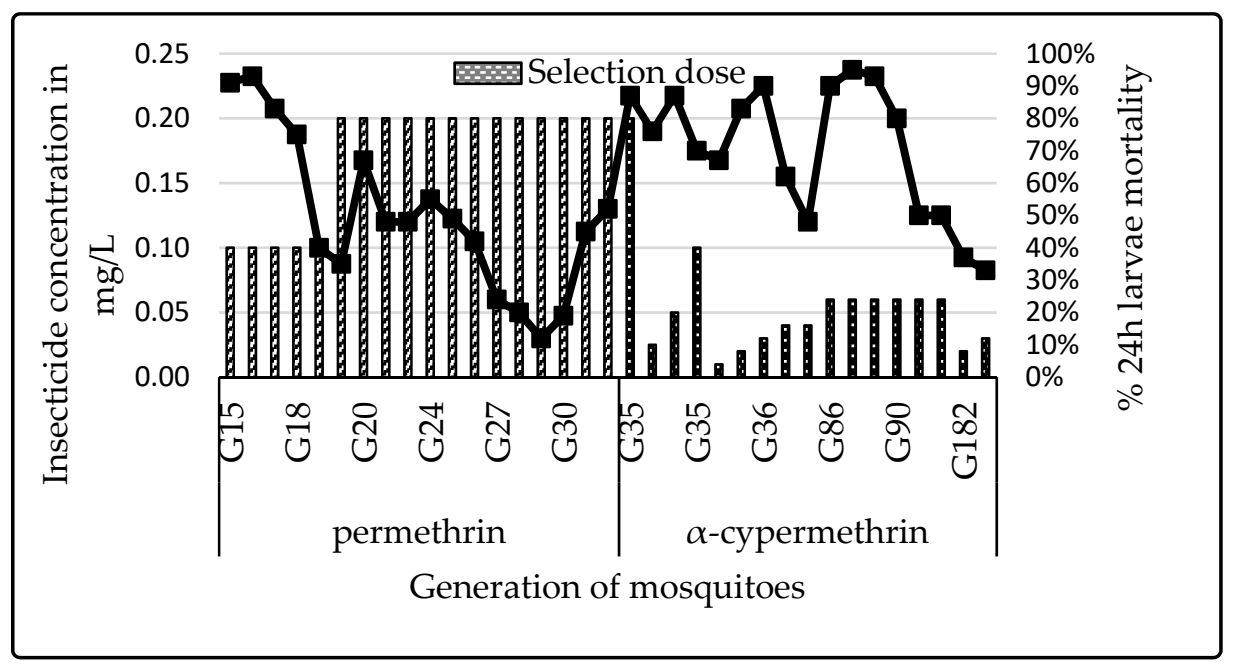

Figure 4. Dynamics of mortality rates of the selected larvae when different pyrethroids were used for the selection at different generations $(G)$.

\subsection{Phenotypic Resistance}

\subsubsection{WHO Susceptibility}

The mortality observed in adult Muleba Kis exposed to permethrin $(0.75 \%)$ test papers in the WHO susceptibility test was high (91\% mortality) in the 17th generation (G17) and decreased to less than $20 \%$ at G25, then increased at G35. This follows a similar trend to the larvae mortality during selection procedures. The larvae selection with permethrin (pyrethroid types I) was not associated with a reduction in adult susceptibility when exposed to alpha-cypermethrin and deltamethrin (pyrethroid type II insecticides) using the WHO susceptibility bioassay at G35. Resistance to permethrin was the highest compared to the two other pyrethroids ( $\alpha$-cypermethrin and $\delta$-methrin) from the 35th to 125th generations. In parallel with permethrin papers, WHO susceptibility bioassays conducted against bendiocarb papers $(0.1 \%)$ and pirimiphos methyl $(0.25 \%)$ resulted in $100 \%$ mortality, indicating that Muleba-Kis is fully susceptible to these insecticides. Mortality to DDT was consistently below $89 \%$ (Figure 5).

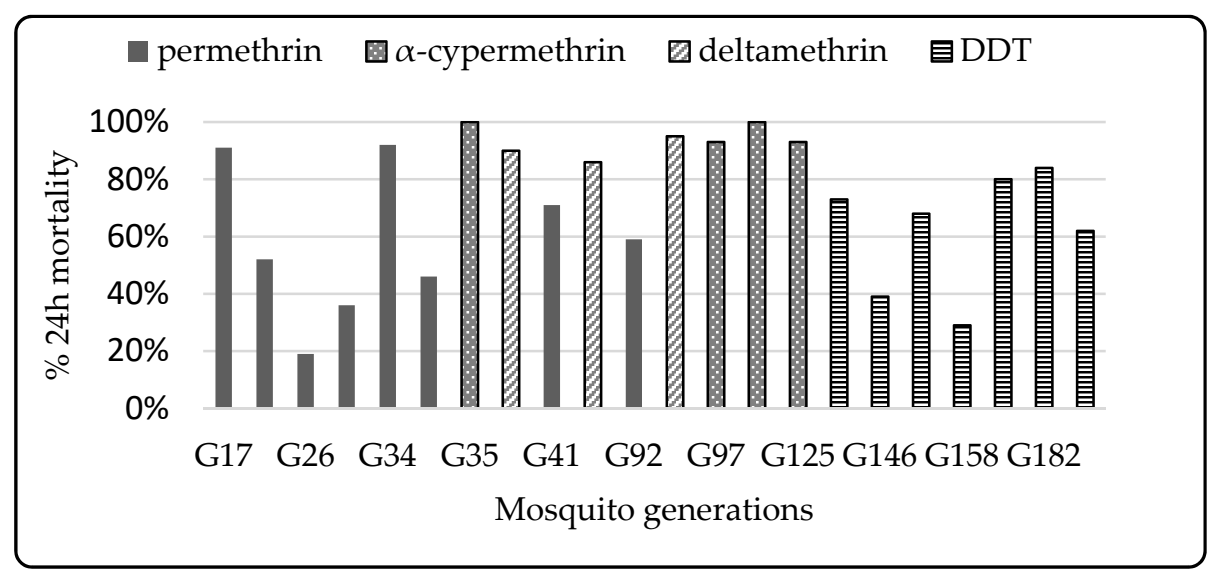

Figure 5. WHO susceptibility profiling of adult An. gambiae Muleba-Kisumu across generations. Mortality less than $90 \%$ indicates resistance, WHO (51). G = Generation.

On average, the Muleba-Kisumu strain's mortality was below the cutoff point $(90 \%)$ when tested against permethrin (type I pyrethroid) and DDT papers. Only results with control mortality that were less than $20 \%$ were considered for analysis; tests when control mortality was higher than $20 \%$ were rejected. When tested against alpha-cypermethrin and deltamethrin (type II pyrethroids), the resistance level was low and above the cutoff value, 
which is suggestive of susceptibility to this pyrethroid class. However, although several mosquito mortalities were above $90 \%$, during the 35th, 89th, 97th, and 125th generations mortalities scored below $98 \%$, which could imply existence of resistance.

\subsubsection{Synergist-Insecticide Bottle Bioassay}

CDC bottle bioassays were conducted with permethrin (PRM) and piperonyl butoxide (PBO) against a susceptible strain and a resistant strain. The susceptible strain showed $>98 \%$ knockdown and mortality after exposure to permethrin, both with and without pre-exposure to PBO. Muleba-Kis showed resistance to PRM (73\% mortality), which was restored to susceptible levels ( $94 \%$ mortality) after pre-exposure to PBO, indicating likely involvement of metabolic resistance mechanism in the An. gambiae Muleba-Kis strain; see Figure 6 below.

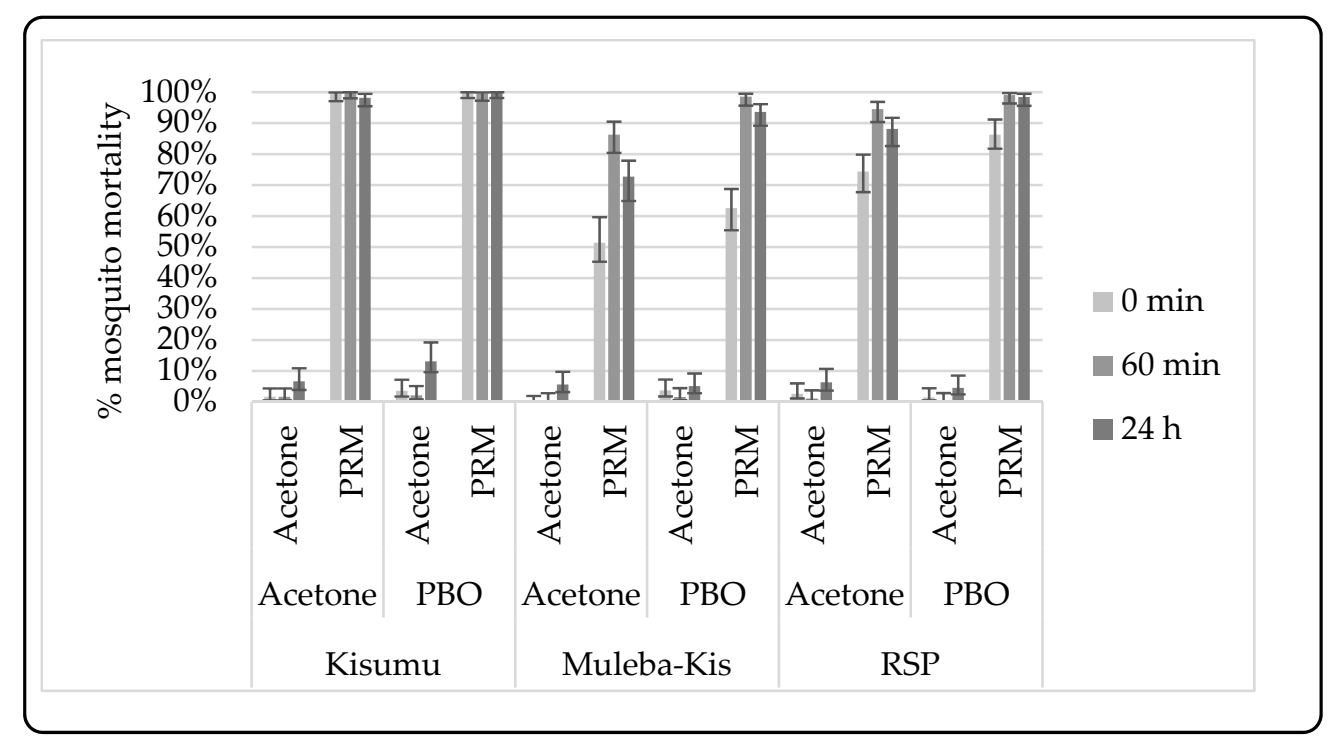

Figure 6. The knockdown and mortality rates of An. gambiae Kisumu and An. gambiae Muleba-Kis with and without PBO pre-exposure. Error bars are equivalent to 95\% confidence intervals. PRM= Permethrin, $\mathrm{PBO}=$ Piperonyl butoxide.

\subsection{Polymerase Chain Reaction (PCR) for Species Identification and Resistance Status}

The $k d r$ L1014S allele reached fixation in An. gambiae s.s. Muleba-Kis populations, coincident with the insecticide selection (Table 1).

Table 1. Molecular assays for Muleba-Kis strain over generations.

\begin{tabular}{|c|c|c|c|c|c|c|c|c|}
\hline \multirow{3}{*}{ Generation } & \multirow{3}{*}{ Number of Samples } & & & \multicolumn{5}{|c|}{ Molecular Assay } \\
\hline & & \multicolumn{2}{|c|}{ Species } & \multicolumn{3}{|c|}{$k d r-\mathrm{E}$} & \multicolumn{2}{|c|}{ Ace-1 } \\
\hline & & $\%$ Ar & $\% \mathrm{Ga}$ & $\% \operatorname{Re}$ & $\%$ RSe & $\%$ SSe & $\%$ RRe & $\%$ SSe \\
\hline G43 & 37 & 0 & 100 & 30 & 27 & 43 & 0 & 100 \\
\hline G99 & 57 & 0 & 100 & 100 & 0 & 0 & 0 & 100 \\
\hline G131 & 50 & 0 & 100 & 100 & 0 & 0 & 0 & 100 \\
\hline G150 & 84 & 0 & 100 & 100 & 0 & 0 & $\mathrm{~N}$ & $\mathrm{~N}$ \\
\hline G162 & 100 & 0 & 100 & 100 & 0 & 0 & $\mathrm{~N}$ & $\mathrm{~N}$ \\
\hline G168 & 84 & 0 & 100 & 100 & 0 & 0 & $\mathrm{~N}$ & $\mathrm{~N}$ \\
\hline G178 & 84 & 0 & 100 & 100 & 0 & 0 & $\mathrm{~N}$ & $\mathrm{~N}$ \\
\hline G188 & 84 & 0 & 100 & 100 & 0 & 0 & $\mathrm{~N}$ & $\mathrm{~N}$ \\
\hline G190 & 84 & 0 & 100 & 100 & 0 & 0 & 0 & 100 \\
\hline G198 & 88 & 0 & 100 & 100 & 0 & 0 & $\mathrm{~N}$ & $\mathrm{~N}$ \\
\hline G204 & 88 & 0 & 100 & 100 & 0 & 0 & $\mathrm{~N}$ & $\mathrm{~N}$ \\
\hline
\end{tabular}

Note: $\mathrm{Ar}=A n$. arabiensis, $\mathrm{Ga}=$ An. gambiae ss, Ace- $1=$ insensitive acetylcholinesterase, $\mathrm{RRe}=$ homozygous mutant, $\mathrm{RSe}=$ heterozygous mutant, $\mathrm{SSe}=$ homozygous susceptible. When an assay was not done it is coded as N. 


\subsection{Resistance Strength of the Selected Colony: CDC Bottle Bioassay}

Results from the CDC Bottle bioassay indicate that An. gambiae Muleba-Kisumu mosquitoes have lower mortality than An. gambiae Kisumu (Figure 7), which is suggestive of a higher level of pyrethroid resistance in the strain.

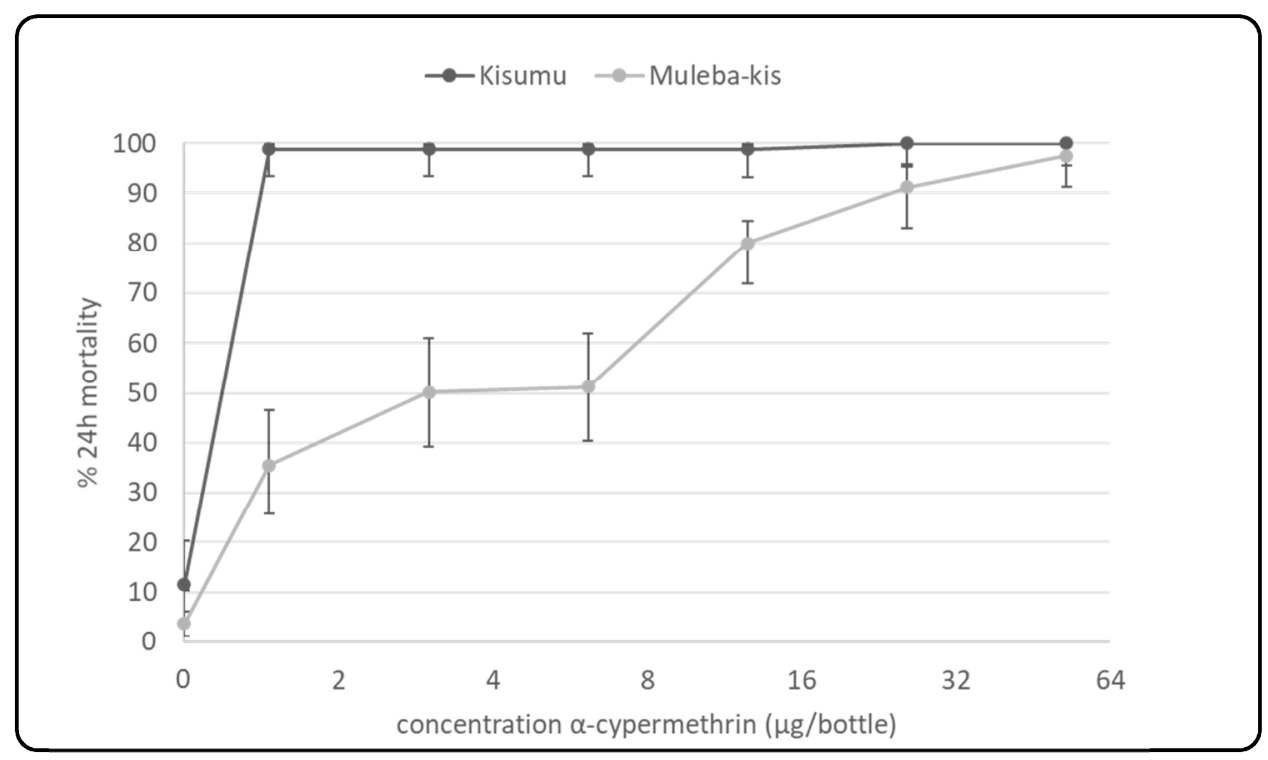

Figure 7. Mortality percentage of An. gambiae Kisumu and An. gambiae Muleba-Kis to varying concentrations of $\alpha$-cypermethrin in CDC bottle bioassay.

At one and two times the diagnostic concentration of alphacypermethrin- $12.5 \mu \mathrm{g} / \mathrm{bottle}$ and $25 \mu \mathrm{g} /$ bottle, respectively - the Muleba-Kis strain showed significantly higher mortality than the Kisumu strain (two-sample $t$-test, $p<0.001$ ). At four times the diagnostic concentration of the same insecticide $-52.5 \mu \mathrm{g} / \mathrm{bottle}$ - there was no significant difference in mortality between the two strains.

Exposure of the Kisumu strain against alphacypermethrin in CDC bottles resulted in high mortality, indicating susceptibility against all doses, starting with a low dosage of $1.466 \mu \mathrm{g} / \mathrm{bottle}$ to the highest at $52.5 \mu \mathrm{g} /$ bottle. On the other hand, exposure to the Muleba-Kis strain showed a dose-response, with mortality as low as $37 \%$ against the lowest dose and increasing to $98 \%$ mortality at four times the diagnostic dose.

\subsection{Biometric Measures for Fitness}

A total of 450 mosquitoes were analyzed: 50 in 2016, 150 in 2017, 150 in 2019, and 100 in 2020.

Data for female mosquito weight and wing length were normally distributed, hence we used the two-sample T-test to compare results between consecutive years. These results indicated that mosquito mean weight in 2017 was significantly higher than all other years, while the other years were similar to each other (Table 2).

Table 2. Dynamics in mosquito wing length across years 2016, 2017, 2019, and 2020.

\begin{tabular}{ccccc}
\hline Year & Samples (N) & Mean Wing Length & $\mathbf{9 5 \%}$ CI & $p$-Value * \\
\hline 2016 & 50 & 2.9504 & $2.8995-3.0013$ & 0.6592 \\
2017 & 150 & 2.9362 & $2.9035-2.9689$ & \\
\hline 2017 & 150 & 2.9362 & $2.9035-2.9689$ & \multirow{2}{*}{0.0001} \\
2019 & 149 & 3.0405 & $3.0066-3.0745$ & \\
\hline 2019 & 149 & 3.0405 & $3.0066-3.0745$ & \multirow{2}{*}{0.0025} \\
2020 & 100 & 2.9532 & $2.9063-3.0001$ & \\
\hline
\end{tabular}

* Two-sample T-test. 
On the other hand, mean wing length was only significantly higher in 2019 compared to the other years (Table 3 ).

Table 3. Dynamics in mosquito weight across years 2016, 2017, 2019, and 2020.

\begin{tabular}{ccccc}
\hline Year & Samples (N) & Mean Weight & $\mathbf{9 5 \% \text { CI }}$ & $p$-Value * \\
\hline 2016 & 50 & 0.0011 & $0.0010-0.0012$ & $<0.0001$ \\
2017 & 150 & 0.0016 & $0.0015-0.0017$ & \\
\hline 2017 & 150 & 0.0016 & $0.0015-0.0017$ & $<0.0001$ \\
2019 & 149 & 0.0012 & $0.0012-0.0013$ & \\
\hline 2019 & 149 & 0.0012 & $0.0012-0.0013$ & \multirow{2}{*}{0.4281} \\
2020 & 100 & 0.0012 & $0.0011-0.0012$ & \\
\hline
\end{tabular}

*Two-sample T-test.

\section{Discussion}

\subsection{Blood-Feeding Challenges with Wild Mosquitoes}

The propensity to feed on guinea pigs was not innate to the wild mosquito population and the colony could not be maintained by other means. The tendency to blood feed on guinea pigs was introduced by out-crossing, which is evidence for the genetic basis of intrinsic host-seeking factors within this Muleba mosquito strain. Host-seeking behaviors drive host choice, which is in turn driven by adaptive advantages that result from feeding on certain host species [58-60]. Wild mosquitoes were collected from bedrooms, which could indicate a preference of these mosquitoes to human blood. Similarly, observations from other studies [61,62] have associated host preference with the availability of host species for blood-feeding, which by their abundance form a readily accessible source of blood. This plasticity in host choice within mosquitoes could also be species- or strainspecific, accounting for differences in adopting a particular host as a blood source between different mosquito species or strains, as observed in this study where wild mosquitoes had a low affinity to guinea pig blood compared to the insectary-reared Kisumu strain.

\subsection{Initial Low Insecticide Resistance Following Cross-Breeding}

A common method used to establish resistant mosquito strain in the insectaries involves collecting wild-resistant mosquitoes and carefully maintaining them as they adapt to insectary conditions, usually going through a narrow bottleneck of few survivors in the first few generations. However, this endeavor has its challenges, such as failure of the wild strain to adapt to insectary temperature, relative humidity, and food; reduced mating; difficulties in blood-feeding on a new blood source; and reduced insecticide resistance. Early generations (15th to 17th) of Muleba-Kis strain in this study exhibited a low level of phenotypic resistance, which could be attributed to the low frequency of resistant alleles inherited from the resistant parent, the Muleba strain. The observed low frequency of resistant alleles, due to standing variation originating from the parental line before pesticide selection, is a phenomenon reported in other studies [63].

\subsection{Impact of Mosquito Developmental Stage Used for Selection}

The selection at the larval stage was chosen for three reasons. First, evolutionary pressure is strongest in young individuals to increase the probability of survival to reproductive maturity. Second, beneficial mutations at an older age can be associated with harmful effects in young individuals [64-66]. Third, by exerting the selection pressure to the aquatic stage of the mosquitoes, there is assurance for successive selection as it is impossible for larvae to survive subsequent selections but only through developing resistance [67]. Additionally, many reports have associated larvae exposure to trace amounts of pesticides with the development of insecticide resistance in malaria vectors [68-71].

In another study where larvae were selected, Shidrawi observed an increase of sevenfold resistance in an Aedes strain with initial moderate resistance when it was selected with DDT for eight generations [50]. When Shidrawi used different insecticides for the same 
strain over a different selection period, he obtained a different resistance outcome. On the other hand, in a study where adult Anopheles were selected [72], using a pyrethroid type II in a period of a single generation the mortality level decreased from $42 \%$ to $18 \%$ over one generation, reflecting an approximately two-fold increase in resistance. Although these results indicate that adult selection induces a more appreciable increase in resistance over a short period when compared to the larval selection, further research is needed to correlate the two stages using the same strain of mosquito and the same insecticide. Additionally, since selection in this study used different insecticides in different generations, it is difficult to determine the period without selection which is taken to reverse resistance to full susceptibility.

\subsection{Impact of Selection Using Pyrethroids}

The resistance of the Muleba-Kis strain was based on a cross between the field An. gambiae s.s. from Muleba District (fixed for L1014S mutation) and the laboratory susceptible $A n$. gambiae s.s. Kisumu strain, resulting in a weak resistance in an out-crossed F1 generation.

To overcome the problem of low resistance, the selection of insect colonies using a sub-lethal concentration of insecticide has been extensively adopted to increase or induce heritable resistance $[73,74]$. Several studies have successfully induced resistance by selecting either adult mosquitoes [50,72,75,76] or larvae [50,77-79]. Following the insecticide selection, a pre-existing low-frequency L1014S mutation became advantageous and was selected to a higher frequency in the population. Results further indicated that out-crossing between resistant and susceptible mosquito followed by positive selection has preserved the L1014S ( $k d r$-e) allele inherited from the resistant parents, as similar results were obtained in other related experiments [80]. Likewise, Song and Leu [81,82] reported the gain of rodenticide resistance alleles by susceptible house mouse Mus musculus domesticus through hybridization with the intrinsically resistant Algerian mouse Mus spretus, followed by introgression under rodenticide selection. The increased insecticide resistance and affinity to guinea pig blood observed in the Muleba-Kis strain could have been inherited via a similar mechanism and is in line with the model for the inheritance of behavioral characters in mosquitoes [83]. However, intermittent selection might be the underlying reason for the observed small rises in susceptibility of the mosquitoes, as measured by WHO susceptibility tests. This reduced resistance due to withdrawal of selection is in agreement with other studies [72]. Apart from maintaining selection for resistance, currently there is no utility for crossing the Muleba-Kis strain to field mosquitoes to maintain a complete genetic background to field populations, as the colony was established to serve as a close representative pyrethroid resistant strain, fixed for the L1014S mutation intended for phase-I and Phase-II studies. However, when the colony is intended for field release, such as in male sterile technique programs or when used to comprehend field population dynamics, it becomes even more important to renew the colony with field material to address the genetic drift and inbreeding effects $[25,26]$.

\subsection{Differential Resistance to Type I and Type II Pyrethroids}

Pyrethroids are classified into type I and type II based on their biological responses. While type I pyrethroids result in low kill with high recovery, type II pyrethroids result in high kill with low recovery. Type I pyrethroids bind preferentially to closed channels while type II binds to open channels [84]. Research has revealed that the level of resistance in houseflies with a super- $k d r$ mechanism is below 100-fold for type I and is over 200-fold for type II pyrethroids [84]. Selection of the same mosquito strain could therefore generate different resistance outcomes depending on the insecticide type, class, and concentration used, among other factors. From this study, selection of larvae with pyrethroid type I correlated with increased tolerance to type I pyrethroid papers (permethrin $0.75 \%$ ) in the WHO susceptibility test, and no significant tolerance was observed against pyrethroid type II papers (alphacypermethrin, deltamethrin) following the selection. A general observation from this study indicates that type I and type II pyrethroids cause different resistance 
patterns, accounting for observed mosquitoes with less sensitivity to type I pyrethroids compared to type II pyrethroids. Similar results have been observed in other studies [85]. This variation is partly attributed to the different structural conformation between type I and type II pyrethroids that affect species selectivity and pyrethroid resistance [86]. Differences in structure and biological response between type I and type II pyrethroids are therefore presumed to be the underlying reasons for the different responses to selection observed in this study.

\subsection{Metabolic Resistance}

Although routine strain characterization by the WHO susceptibility test suggests that $k d r$ was the underlying mechanism for resistance, limited PBO synergist bottle bioassay, which was done only once, indicated that mosquitoes' pre-exposure to PBO results in an increased susceptibility to permethrin by $20 \%$, suggesting the role of metabolic resistance in this strain. However, the high susceptibility of this strain to bendiocarb and pirimiphosmethyl suggests a narrow role by metabolic resistance which requires more tests to confirm its contribution to an overall resistance. There is a need for testing for the gene expression levels, especially the CYP 450 genes which have widely been linked with metabolic resistance in malaria vectors across Sub-Saharan African [87].

\subsection{Intermittent Quality Control Checks and Regular Strain Authentication}

In this study, the quality of the mosquito colonies was checked to ensure that the rearing and selection procedures did not lead to contamination between strains or negative effects on the mosquito's weight or size. Underweight or undersized mosquitoes are not suitable for insecticide-testing assays, as they are more likely to be knocked down or killed by a given concentration of the insecticide. Furthermore, consistency of size is a good measure of the quality of rearing and helps to produce consistent and reproducible results provided that other rearing factors such as larval density, nutrition, environmental conditions, and microbial infection are controlled. The obtained results indicated that, despite out-crossing and insecticide selection of the strain, the weight and wing length remained fairly similar across the years, with the weight varying by only $0.001 \mathrm{~g}$ across four years, while wing length varied within $0.0142 \mathrm{~mm}$ and $0.0028 \mathrm{~mm}$.

Contamination between strains held in the same facility is a regular error in mosquito rearing, especially when the same or closely related species are kept nearby $[17,18,88]$. The PAMVERC Test Facility keeps different strains of An. gambiae s.l. in different rooms and performs regular species identification using the PCR method [53] and resistance status checks to monitor for any cross-contamination. Results from characterizing the MulebaKisumu strain indicated that this species was identified as An. gambiae s.s. throughout the study, implying the absence of species contamination. Anopheles gambiae Muleba-Kisumu population was initially found to be partially resistant with only $30 \%$ having $k d r$ fixed, but later $k d r$ L1014S allele reached fixation in A. gambiae s.s. Muleba-Kisumu populations following the insecticide selection. These same populations exhibit strong degrees of phenotypic resistance to DDT and pyrethroid class I insecticides (permethrin).

\subsection{Effect of Mosquito Weight and Wing Length on Phenotypic Resistance}

Data for mosquito weight from 2016 to 2020 were normally distributed. The observed deviation in 2017 in mosquito weight could partly be attributed to changes in larvae food preparation. From 2016 to 2017, the preparation of fish flakes which are used as larvae food were microwaved at 150 degrees Celsius. However, this practice was terminated in 2018 as it was suspected to increase the nutrient content of larvae food. An increase in nutrient content or food is reported to lead to longer wings [89]. Results for median weight from 2016 to 2017 when there was no selection increased; from 2017 to 2019 weight decreased significantly; then from 2019 to 2020 the selection was ongoing and mean weight remained constant. The observed increase in weight before selection was mainly due to the nutrition regimen on the larvae. On the generations from 146-158, mosquito weight was 
higher, with resistance thresholds equivalent to later generations (182th to 202th) when there was relatively low but maintained weight with ongoing selection. Maintaining the mosquitoes' weight is crucial, as it is the main determinant of insecticide susceptibility, and heavier mosquitoes are more likely to survive insecticide treatment [90]. Maintaining mosquito weight from year to year is essential in getting the correct interpretation from the WHO discriminatory concentrations [90], which is fundamental in both monitoring resistance development progress and strain authentication. On the other hand, mosquito wing length results were maintained except for 2019, where they were significantly higher relative to other years. Results obtained in this study indicate that progress and status of insecticide resistance are attributed to insecticide selection and are not confounded by weight or wing length. Furthermore, in this experiment there was a detectable difference between weight and wing length, however, there were no sufficient data to prove a direct correlation between wing length and mosquito weight. Although some studies [91] have observed a correlation between weight and wing length, other studies have reported a lack of correlation between wing length and weight [54,92].

\section{Conclusions}

Since its establishment, the PAMVERC Test Facility has played an important role as a key African research player in the chain of insecticide development, particularly in screening new active ingredients for mosquito control. Successful establishment of the Muleba-Kis strain in the insectary marks an important step in the colonization of a representative East African wild Anopheles population characterized with $k d r$-east mutation [30]. This insectary colony enables the evaluation of vector control tools under the current East African insecticide resistance challenge. This study has also demonstrated that bloodfeeding failure and low insecticide resistance in colonized mosquitoes can be overcome by out-crossing desired traits between mosquito strains followed by intermittent insecticide selection at the larval stage. It is worth mentioning that, with the interest in developing and bringing new insecticides into the market, it is crucial to quantify the fitness cost associated with resistance [93], and that although our test facility has managed to successfully create a resistant line through the described methodology with comparison to cited separate studies, further research is needed to perform a direct comparison between various selection methods and to assess the level and duration it takes to establish resistant lines in the same mosquito strain. The capacity to establish resistant mosquitoes allows for assessment of new insecticides for efficacy, cross-resistance, and the likelihood of resistance development to a novel insecticide, therefore providing an early alert to plan for an effective pre-emptive resistance management program.

Author Contributions: Conceptualization, S.A., A.W., R.A. and N.P.; data curation, S.A., R.K., F.T. and M.K.; formal analysis, S.A., A.W., B.S., F.T. and M.K.; investigation, S.A., J.S., A.W. and N.P.; methodology, S.A., J.S., J.M., B.S., R.A. and M.K.; project administration, S.A.; supervision, S.A. and A.W.; validation, J.S.; visualization, M.K.; writing—original draft, S.A.; writing—review \& editing, J.S., J.M., R.K. and M.K. All authors have read and agreed to the published version of the manuscript.

Funding: This research received no external funding.

Institutional Review Board Statement: Not applicable.

Informed Consent Statement: Not applicable.

Data Availability Statement: Datasets generated and analyzed are presented in a summarized way in this article. Full datasets will be made available from the corresponding author upon rational request.

Acknowledgments: For discussion, including some eloquent objections that sharpened our thinking, we thank Rosemary Lees. We also thanks Frank W. Mosha for his encouragement throughout this study and his invaluable comments. We also thank George Holliday for sharing the synergistinsecticide bioassay results by using the Anopheles gambiae Muleba-Kis. We also thank the KCMUCo and KCMUCo PAMVERC in particular for allowing research to be conducted using their facility and resources. 
Conflicts of Interest: The authors declare no conflict of interest.

\section{References}

1. malERA Consultative Group on Vector Control. A research agenda for malaria eradication: Vector control. PLoS Med. 2011, 8, e1000401.

2. Miller, J.E.; Lindsay, S.W.; Armstrong, J.R. Experimental hut trials of bednets impregnated with synthetic pyrethroid or organophosphate insecticide for mosquito control in The Gambia. Med. Vet. Entomol. 1991, 5, 465-476. [CrossRef]

3. Lindsay, S.W.; Adiamah, J.H.; Miller, J.E.; Armstrong, J.R. Pyrethroid-treated bednet effects on mosquitoes of the Anopheles gambiae complex in The Gambia. Med. Vet. Entomol. 1991, 5, 477-483. [CrossRef]

4. Ranson, H.; N'guessan, R.; Lines, J.; Moiroux, N.; Nkuni, Z.; Corbel, V. Pyrethroid resistance in African anopheline mosquitoes: What are the implications for malaria control? Trends Parasitol. 2011, 27, 91-98. [CrossRef] [PubMed]

5. World Health Organization. WHO Specifications for Public Health Pesticides, Permethrin (25:75 cis:trans, Nonracemic). 2015 Available online: https:/ / www.who.int/whopes / quality /Permethrin_25:75_nonracemic_specs_eval_July_2015.pdf?ua=1 (accessed on 1 December 2020).

6. World Health Organization. Deltamethrin Long-Lasting (Incorporated into Filaments) Insecticidal Net. 2011. Available online: https:/ / www.who.int/whopes/quality / Alpha-cypermethrin_incorporated_LN_specs_eval_WHO_October_2014.pdf? ua $=1$ (accessed on 1 December 2020).

7. World Health Organization. Deltamethrin Long-Lasting (Incorporated into Filaments) Insecticidal Net. 2011. Available online: https://www.who.int/whopes/quality/Deltamethrin_LN_incorporated_into_filaments_WHO_spec_eval_Sep_2011.pdf (accessed on 1 December 2020).

8. Bradberry, S.M.; Cage, S.A.; Proudfoot, A.T.; Vale, J.A. Poisoning due to pyrethroids. Toxicol Rev. 2005, 24, 93-106. [CrossRef]

9. Toé, K.H.; Jones, C.M.; N’Fale, S.; Ismail, H.M.; Dabiré, R.K.; Ranson, H. Increased pyrethroid resistance in malaria vectors and decreased bed net effectiveness, Burkina Faso. Emerg. Infect. Dis. 2014, 20, 1691-1696. [CrossRef]

10. Zaim, M.; Guillet, P. Alternative insecticides: An urgent need. Trends Parasitol. 2002, 18, 161-163. [CrossRef]

11. World Health Organization. Global Plan for Insecticide Resistance Management in Malaria Vectors; World Health Organization: Geneva, Switzerland, 2012.

12. Hemingway, J.; Shretta, R.; Wells, T.N.C.; Bell, D.; Djimdé, A.A.; Achee, N.; Qi, G. Tools and strategies for malaria control and elimination: What do we need to achieve a grand convergence in malaria? PLoS Biol. 2016, 14, e1002380. [CrossRef] [PubMed]

13. Oxborough, R.M.; N'Guessan, R.; Kitau, J.; Tungu, P.K.; Malone, D.; Mosha, F.W.; Rowland, M.W. A new class of insecticide for malaria vector control: Evaluation of mosquito nets treated singly with indoxacarb (oxadiazine) or with a pyrethroid mixture against Anopheles gambiae and Culex quinquefasciatus. Malar. J. 2015, 14, 353. [CrossRef] [PubMed]

14. Insecticide Discovery \& Development. 2019. Available online: https://www.ivcc.com/research-development/insecticidediscovery-and-development/ (accessed on 1 December 2020).

15. Lees, R.; Praulins, G.; Davies, R.; Brown, F.; Parsons, G.; White, A.; Ranson, H.; Small, G.; Malone, D. A testing cascade to identify repurposed insecticides for next-generation vector control tools: Screening a panel of chemistries with novel modes of action against a malaria vector. Gates Open Res. 2019, 3, 1464. [CrossRef] [PubMed]

16. World Health Organization. Guidelines for Laboratory and Field Testing of Long-Lasting Insecticidal Nets; WHO/HTM/NTD/WHOPES/ 2013.1; World Health Organization: Geneva, Switzerland, 2013.

17. Benedict, M.Q.; Burt, A.; Capurro, M.L.; de Barro, P.; Handler, A.M.; Hayes, K.R.; Marshall, J.M.; Tabachnick, W.J.; Adelman, Z.L. Recommendations for Laboratory Containment. Vector Borne Zoonotic Dis. 2018, 18, 2-13. [CrossRef] [PubMed]

18. Gloria-Soria, A.; Soghigian, J.; Kellner, D.; Powell, J.R. Genetic diversity of laboratory strains and implications for research: The case of Aedes aegypti. PLoS Negl. Trop. Dis. 2019, 13, e0007930. [CrossRef] [PubMed]

19. Hoffmann, A.A.; Hallas, R.; Sinclair, C.; Partridge, L. Rapid loss of stress resistance in Drosophila melanogaster under adaptation to laboratory culture. Evol. Int. J. Org. Evol. 2001, 55, 436-438. [CrossRef]

20. Bravo, I.S.J.; Zucoloto, F.S. Performance and feeding behavior of Ceratitis capitata: Comparison of a wild population and a laboratory population. Entomol. Exp. Appl. 1998, 87, 67-72. [CrossRef]

21. Matos, M.; Rose, M.R.; Rocha Pité, M.T.; Rego, C.; Avelar, T. Adaptation to the laboratory environment in Drosophila subobscura. J. Evol. Biol. 2000, 13, 9-19. [CrossRef]

22. Diamantidis, A.D.; Carey, J.R.; Nakas, C.T.; Papadopoulos, N.T. Ancestral populations perform better in a novel environment: Domestication of Mediterranean fruit fly populations from five global regions. Biol. J. Linn. Soc. 2011, 102, 334-345. [CrossRef]

23. Gingerich, P.D. Rates of evolution: Effects of time and temporal scaling. Science 1983, 222, 159-161. [CrossRef]

24. Hendry, A.P.; Kinnison, M.T. Perspective: The pace of modern life: Measuring rates of contemporary microevolution. Evolution 1999, 53, 1637. [CrossRef]

25. Baeshen, R.; Ekechukwu, N.E.; Toure, M.; Paton, D.; Coulibaly, M.; Traoré, S.F.; Tripet, F. Differential effects of inbreeding and selection on male reproductive phenotype associated with the colonization and laboratory maintenance of Anopheles gambiae. Malar. J. 2014, 13, 19. [CrossRef]

26. Hoffmann, A.A.; Ross, P.A. Rates and Patterns of Laboratory Adaptation in (Mostly) Insects. J. Econ. Entomol. 2018, 111, 501-509. [CrossRef] 
27. Matowo, J.; Kulkarni, M.A.; Mosha, F.W.; Oxborough, R.M.; Kitau, J.A.; Tenu, F.; Rowland, M. Biochemical basis of permethrin resistance in Anopheles arabiensis from Lower Moshi, north-eastern Tanzania. Malar. J. 2010, 9, 193. [CrossRef] [PubMed]

28. Matowo, J.; Kitau, J.; Kaaya, R.; Kavishe, R.; Wright, A.; Kisinza, W.; Kleinschmidt, I.; Mosha, F.; Rowland, M.; Protopopoff, N. Trends in the selection of insecticide resistance in Anopheles gambiae s.l. mosquitoes in northwest Tanzania during a community randomized trial of longlasting insecticidal nets and indoor residual spraying: Selection of insecticide resistance in An. gambiae. Med. Vet. Entomol. 2015, 29, 51-59. [PubMed]

29. Kuno, G. Early history of laboratory breeding of Aedes aegypti (Diptera: Culicidae) Focusing on the origins and use of selected strains. J. Med. Entomol. 2010, 47, 957-971. [CrossRef]

30. Ranson, H.; Jensen, B.; Vulule, J.M.; Wang, X.; Hemingway, J.; Collins, F.H. Identification of a point mutation in the voltage-gated sodium channel gene of Kenyan Anopheles gambiae associated with resistance to DDT and pyrethroids. Insect Mol. Biol. 2000, 9 , 491-497. [CrossRef]

31. Stump, A.D.; Atieli, F.K.; Vulule, J.M.; Besansky, N.J. Dynamics of the pyrethroid knockdown resistance allele in western Kenyan populations of Anopheles gambiae in response to insecticide-treated bed net trials. Am. J. Trop. Med. Hyg. 2004, 70, 591-596. [CrossRef]

32. Nwane, P.; Etang, J.; Chouaïbou, M.; Toto, J.C.; Mimpfoundi, R.; Simard, F. Kdr-based insecticide resistance in Anopheles gambiae s.s. populations in Cameroon: Spread of the L1014F and L1014S mutations. BMC Res. Notes 2011, 4, 463. [CrossRef]

33. Namountougou, M.; Diabaté, A.; Etang, J.; Bass, C.; Sawadogo, S.P.; Gnankinié, O.; Baldet, T.; Martin, T.; Chandre, F.; Simard, F.; et al. First report of the L1014S kdr mutation in wild populations of Anopheles gambiae M and S molecular forms in Burkina Faso (West Africa). Acta Trop. 2013, 125, 123-127. [CrossRef]

34. Etang, J.; Fondjo, E.; Chandre, F.; Morlais, I.; Brengues, C.; Nwane, P.; Chouaibou, M.; Ndjemai, H.; Simard, F. First report of knockdown mutations in the malaria vector Anopheles gambiae from Cameroon. Am. J. Trop. Med. Hyg. 2006, 74, 795-797. [CrossRef]

35. O'Reilly, A.O.; Khambay, B.P.S.; Williamson, M.S.; Field, L.M.; Wallace, B.A.; Davies, T.G.E. Modelling insecticide-binding sites in the voltage-gated sodium channel. Biochem. J. 2006, 396, 255-263. [CrossRef]

36. Reimer, L.; Fondjo, E.; Patchoké, S.; Diallo, B.; Lee, Y.; Ng, A.; Ndjemai, H.M.; Atangana, J.; Traore, S.F.; Lanzaro, G.; et al. Relationship between $k d r$ mutation and resistance to pyrethroid and DDT insecticides in natural populations of Anopheles gambiae. J. Med. Entomol. 2008, 45, 260-266. [CrossRef] [PubMed]

37. Protopopoff, N.; Matowo, J.; Malima, R.; Kavishe, R.; Kaaya, R.; Wright, A.; West, P.A.; Kleinschmidt, I.; Kisinza, W.; Mosha, F.W.; et al. High level of resistance in the mosquito Anopheles gambiae to pyrethroid insecticides and reduced susceptibility to bendiocarb in north-western Tanzania. Malar. J. 2013, 12, 149. [CrossRef] [PubMed]

38. Protopopoff, N.; Mosha, J.F.; Lukole, E.; Charlwood, J.D.; Wright, A.; Mwalimu, C.D.; Manjurano, A.; Mosha, F.W.; Kisinza, W.; Kleinschmidt, I.; et al. Effectiveness of a long-lasting piperonyl butoxide-treated insecticidal net and indoor residual spray interventions, separately and together, against malaria transmitted by pyrethroid-resistant mosquitoes: A cluster, randomised controlled, two-by-two factorial design trial. Lancet 2018, 391, 1577-1588. [PubMed]

39. Ramphul, U.; Boase, T.; Bass, C.; Okedi, L.M.; Donnelly, M.J.; Müller, P. Insecticide resistance and its association with target-site mutations in natural populations of Anopheles gambiae from eastern Uganda. Trans. R. Soc. Trop. Med. Hyg. 2009, 103, 1121-1126. [CrossRef]

40. Kabula, B.; Kisinza, W.; Tungu, P.; Ndege, C.; Batengana, B.; Kollo, D.; Malima, R.; Kafuko, J.; Mohamed, M.; Magesa, S. Co-occurrence and distribution of East (L1014S) and West (L1014F) African knock-down resistance in Anopheles gambiae sensu lato population of Tanzania. Trop. Med. Int. Health 2014, 19, 331-341. [CrossRef] [PubMed]

41. Kawada, H.; Dida, G.O.; Ohashi, K.; Komagata, O.; Kasai, S.; Tomita, T.; Sonye, G.; Maekawa, Y.; Mwatele, C.; Njenga, S.M.; et al. Multimodal pyrethroid resistance in malaria vectors, Anopheles gambiae s.s., Anopheles arabiensis, and Anopheles funestus s.s. in western Kenya. PLoS ONE 2011, 6, e22574. [CrossRef] [PubMed]

42. Abeku, T.A.; Helinski, M.E.H.; Kirby, M.J.; Ssekitooleko, J.; Bass, C.; Kyomuhangi, I.; Okia, M.; Magumba, G.; Meek, S.R. Insecticide resistance patterns in Uganda and the effect of indoor residual spraying with bendiocarb on $k d r$ L1014S frequencies in Anopheles gambiae s.s. Malar. J. 2017, 16, 156. [CrossRef] [PubMed]

43. Munywoki, D.N.; Kokwaro, E.D.; Mwangangi, J.M.; Muturi, E.J.; Mbogo, C.M. Insecticide resistance status in Anopheles gambiae (s.1.) in coastal Kenya. Parasites Vectors 2021, 14, 207. [CrossRef]

44. Kisinza, W.N.; Nkya, T.E.; Kabula, B.; Overgaard, H.J.; Massue, D.J.; Mageni, Z.; Greer, G.; Kaspar, N.; Mohamed, M.; Moore, S.; et al. Multiple insecticide resistance in Anopheles gambiae from Tanzania: A major concern for malaria vector control. Malar. J. 2017, 16, 439. [CrossRef]

45. Weill, M.; Luffalla, G.; Mogensen, K.; Chandre, F.; Berthomieu, A.; Berticat, C.; Pasteur, N.; Philips, A.; Fort, P.; Raymond, M. Insecticide resistance in mosquito vectors. Nature 2003, 423, 136-137. [CrossRef]

46. West, P.A.; Protopopoff, N.; Wright, A.; Kivaju, Z.; Tigererwa, R.; Mosha, F.W.; Kisinza, W.; Rowland, M.; Kleinschmidt, I. Indoor Residual Spraying in combination with Insecticide-Treated Nets compared to Insecticide-Treated Nets alone for protection against malaria: A Cluster Randomised Trial in Tanzania. PLoS Med. 2014, 11, e1001630. [CrossRef]

47. Bass, C.; Williamson, M.S.; Wilding, C.S.; Donnelly, M.J.; Field, L.M. Identification of the main malaria vectors in the Anopheles gambiae species complex using a TaqMan real-time PCR assay. Malar. J. 2007, 9, 155. [CrossRef] 
48. Ranson, H.; Lissenden, N. Insecticide resistance in African Anopheles mosquitoes: A worsening situation that needs urgent action to maintain malaria control. Trends Parasitol. 2016, 32, 187-196. [CrossRef] [PubMed]

49. Moyes, C.L.; Athinya, D.K.; Seethaler, T.; Battle, K.E.; Sinka, M.; Hadi, M.P.; Hemingway, J.; Coleman, M.; Hancock, P.A. Evaluating insecticide resistance across African districts to aid malaria control decisions. Proc. Natl. Acad. Sci. USA 2020, 117, 22042-22050. [CrossRef] [PubMed]

50. Shidrawi, G.R. Laboratory tests on mosquito tolerance to insecticides and the development of resistance by Aedes aegypti. Bull. World Health Organ. 1957, 17, 377-411. [PubMed]

51. World Health Organization. Test Procedures for Insecticide Resistance Monitoring in Malaria Vector Mosquitoes; World Health Organization: Geneva, Switzerland, 2016.

52. Brogdon, W.G.; McAllister, J.C. Simplification of adult mosquito bioassays through use of time-mortality determinations in glass bottles. J. Am. Mosq. Control Assoc. 1998, 14, 159-164.

53. Bass, C.; Nikou, D.; Vontas, J.; Williamson, M.S.; Field, L.M. Development of high-throughput real-time PCR assays for the identification of insensitive acetylcholinesterase (ace-1R) in Anopheles gambiae. Pestic. Biochem. Physiol. 2010, 96, 80-85. [CrossRef]

54. Nasci, R.S. Relationship of wing length to adult dry weight in several mosquito species (Diptera: Culicidae). J. Med. Entomol. 1990, 27, 716-719. [CrossRef]

55. Yeap, H.L.; Endersby, N.M.; Johnson, P.H.; Ritchie, S.A.; Hoffmann, A.A. Body size and wing shape measurements as quality indicators of Aedes aegypti mosquitoes destined for field release. Am. J. Trop. Med. Hyg. 2013, 89, 78-92. [CrossRef]

56. Bookstein, F.L. Morphometric Tools for Landmark Data: Geometry and Biology; Cambridge University Press: Cambridge, UK, 1997.

57. STATA. Base Reference Manual; Stata Press: College Station, TX, USA, 2019. Available online: https://www.stata.com/bookstore/ base-reference-manual/ (accessed on 26 February 2020).

58. Pasteur, N.; Raymond, M. Insecticide resistance genes in mosquitoes: Their mutations, migration, and selection in field populations. J. Hered. 1996, 87, 444-449. [CrossRef]

59. Stone, C.; Gross, K. Evolution of host preference in anthropophilic mosquitoes. Malar. J. 2018, 17, 257. [CrossRef]

60. Main, B.J.; Lee, Y.; Ferguson, H.M.; Kreppel, K.S.; Kihonda, A.; Govella, N.J.; Collier, T.C.; Cornel, A.J.; Eskin, E.; Kang, E.-Y.; et al. The genetic basis of host preference and resting behavior in the major African malaria vector, Anopheles arabiensis. PLoS Genet. 2016, 12, e1006303. [CrossRef]

61. Kilpatrick, A.M.; Kramer, L.D.; Jones, M.J.; Marra, P.P.; Daszak, P. West Nile virus epidemics in North America are driven by shifts in mosquito feeding behavior. PLoS Biol. 2006, 4, e82. [CrossRef] [PubMed]

62. Takken, W.; Verhulst, N.O. Host preferences of blood-feeding mosquitoes. Annu. Rev. Entomol. 2013, 58, 433-453. [CrossRef]

63. Barrett, R.D.H.; Schluter, D. Adaptation from standing genetic variation. Trends Ecol. Evol. 2008, 23, 38-44. [CrossRef]

64. Fisher, R.A. The Genetical Theory of Natural Selection: A Complete Variorum Edition; Bennett, H., Ed.; Oxford University Press: London, UK, 1999.

65. Darlington, C.D. New paths in genetics. Nature 1942, 149, 317. [CrossRef]

66. Koella, J.C.; Lynch, P.A.; Thomas, M.B.; Read, A.F. Towards evolution-proof malaria control with insecticides. Evol. Appl. 2009, 2, 469-480. [CrossRef] [PubMed]

67. Hawkins, N.J.; Bass, C.; Dixon, A.; Neve, P. The evolutionary origins of pesticide resistance. Biol. Rev. 2019, 94, 135-155. [CrossRef]

68. Nkya, T.E.; Poupardin, R.; Laporte, F.; Akhouayri, I.; Mosha, F.; Magesa, S.; Kisinza, W.; David, J.-P. Impact of agriculture on the selection of insecticide resistance in the malaria vector Anopheles gambiae: A multigenerational study in controlled conditions. Parasites Vectors 2014, 7, 480.

69. Kudom, A.A.; Anane, L.N.; Afoakwah, R.; Adokoh, C.K. Relating high insecticide residues in larval breeding habitats in urban residential areas to the selection of pyrethroid resistance in Anopheles gambiae s.L. (Diptera: Culicidae) in Akim Oda, Ghana. J. Med. Entomol. 2018, 55, 490-495. [CrossRef] [PubMed]

70. Wang, Y.; Cheng, P.; Jiao, B.; Song, X.; Wang, H.; Wang, H.; Wang, H.; Huang, X.; Liu, H.; Gong, M. Investigation of mosquito larval habitats and insecticide resistance in an area with a high incidence of mosquito-borne diseases in Jining, Shandong Province. PLoS ONE 2020, 15, e0229764. [CrossRef]

71. Talom, A.D.; Essoung, M.A.; Gbankoto, A.; Tchigossou, G.; Akoton, R.; Sahabi, B.B.A.; Atoyebi, S.M.; Kuate, A.F.; Verspoor, V.R.; Tamò, M.; et al. A preliminary analysis on the effect of copper on Anopheles coluzzii insecticide resistance in vegetable farms in Benin. Sci. Rep. 2020, 10, 6392. [CrossRef] [PubMed]

72. Machani, M.G.; Ochomo, E.; Zhong, D.; Zhou, G.; Wang, X.; Githeko, A.K.; Yan, G.; Afrane, Y.A. Phenotypic, genotypic and biochemical changes during pyrethroid resistance selection in Anopheles gambiae mosquitoes. Sci. Rep. 2020, 10, 19063. [CrossRef]

73. Brown, T.M.; Payne, G.T. Experimental selection for insecticide resistance. J. Econ. Entomol. 1988, 81, 49-56. [CrossRef] [PubMed]

74. Afzal, M.B.S.; Shad, S.A.; Ejaz, M.; Serrao, J.E. Laboratory selection, cross-resistance, and estimations of realized heritability of indoxacarb resistance in Phenacoccus solenopsis (Homoptera: Pseudococcidae). Pest Manag. Sci. 2020, 76, 161-168. [CrossRef] [PubMed]

75. Williams, J.; Flood, L.; Praulins, G.; Ingham, V.A.; Morgan, J.; Lees, R.S.; Ranson, H. Characterisation of Anopheles strains used for laboratory screening of new vector control products. Parasites Vectors 2019, 12, 522. [CrossRef]

76. Hunt, R.H.; Brooke, B.D.; Pillay, C.; Koekemoer, L.L.; Coetzee, M. Laboratory selection for and characteristics of pyrethroid resistance in the malaria vector Anopheles funestus. Med. Vet. Entomol. 2005, 19, 271-275. [CrossRef] 
77. Subramaniam, S.; Aris, E.M.; Ahmad, N.W.; Lee, H.L.; Azahari, A.H. The development of resistance and susceptibility of Aedes aegypti larvae and adult mosquitoes against selection pressure to malathion, permethrin and temephos insecticides and its cross-resistance relationship against propoxur. Malays. J. Sci. 2006, 25, 1-13.

78. Saleh, M.S.; El-Meniawi, F.A.; Kelada, N.L.; Zahran, H.M. Resistance development in mosquito larvae Culex pipiens to the bacterial agent Bacillus thuringiensis var. israelensis. J. Appl. Entomol. 2003, 127, 29-32. [CrossRef]

79. Viana-Medeiros, P.F.; Bellinato, D.F.; Valle, D. Laboratory selection of Aedes aegypti field populations with the organophosphate malathion: Negative impacts on resistance to deltamethrin and to the organophosphate temephos. PLoS Negl. Trop. Dis. 2018, 12, e0006734. [CrossRef]

80. Hedrick, P.W. Adaptive introgression in animals: Examples and comparison to new mutation and standing variation as sources of adaptive variation. Mol. Ecol. 2013, 22, 4606-4618. [CrossRef]

81. Song, Y.; Endepols, S.; Klemann, N.; Richter, D.; Matuschka, F.-R.; Shih, C.-H.; Nachman, M.W.; Kohn, M.H. Adaptive introgression of anticoagulant rodent poison resistance by hybridization between old world mice. Curr. Biol. 2011, 21, 1296-1301. [CrossRef]

82. Liu, K.J.; Steinberg, E.; Yozzo, A.; Song, Y.; Kohn, M.H.; Nakhleh, L. Interspecific introgressive origin of genomic diversity in the house mouse. Proc. Natl. Acad. Sci. USA 2015, 112, 196-201. [CrossRef]

83. Trpis, M.; Hausermann, W. Genetics of house-entering behaviour in East African populations of Aedes aegypti (L.) (Diptera: Culicidae) and its relevance to speciation. Bull. Entomol. Res. 1978, 68, 521-532. [CrossRef]

84. Soderlund, D.M.; Clark, J.M.; Sheets, L.P.; Mullin, L.S.; Piccirillo, V.J.; Sargent, D.; Stevens, J.T.; Weiner, M.L. Mechanisms of pyrethroid neurotoxicity: Implications for cumulative risk assessment. Toxicology 2002, 171, 3-59. [CrossRef]

85. Kamgang, B.; Wilson-Bahun, T.A.; Yougang, A.P.; Lenga, A.; Wondji, C.S. Contrasting resistance patterns to type I and II pyrethroids in two major arbovirus vectors Aedes aegypti and Aedes albopictus in the Republic of the Congo, Central Africa. Infect. Dis. Poverty 2020, 9, 23. [CrossRef]

86. Casida, J.E.; Durkin, K.A. Neuroactive insecticides: Targets, selectivity, resistance, and secondary effects. Annu. Rev. Entomol. 2013, 58, 99-117. [CrossRef] [PubMed]

87. Müller, P.; Warr, E.; Stevenson, B.J.; Pignatelli, P.M.; Morgan, J.C.; Steven, A.; Yawson, A.E.; Mitchell, S.N.; Ranson, H.; Hemingway, J.; et al. Field-caught permethrin-resistant Anopheles gambiae overexpress CYP6P3, a P450 that metabolises pyrethroids. PLoS Genet. 2008, 4, e1000286. [CrossRef] [PubMed]

88. Wilkins, E.E.; Marcet, P.L.; Sutcliffe, A.C. Authentication scheme for routine verification of genetically similar laboratory colonies: A trial with Anopheles gambiae. BMC Biotechnol. 2009, 9, 91. [CrossRef] [PubMed]

89. Valerio, L.; Collins, C.M.; Lees, R.S.; Benedict, M.Q. Benchmarking vector arthropod culture: An example using the African malaria mosquito, Anopheles gambiae (Diptera: Culicidae). Malar. J. 2016, 15, 262. [CrossRef]

90. Owusu, H.F.; Chitnis, N.; Müller, P. Insecticide susceptibility of Anopheles mosquitoes' changes in response to variations in the larval environment. Sci. Rep. 2017, 7, 3667. [CrossRef]

91. Petersen, V.; Marchi, M.J.; Natal, D.; Marrelli, M.T.; Barbosa, A.C.; Suesdek, L. Assessment of the correlation between wing size and body weight in captive Culex quinquefasciatus. Rev. Soc. Bras. Med. Trop. 2016, 49, 508-511. [CrossRef]

92. Siegel, J.P.; Novak, R.J.; Lampman, R.L.; Steinly, B.A. Statistical appraisal of the weight-wing length relationship of mosquitoes. J. Med. Entomol. 1992, 29, 711-714. [CrossRef]

93. Martins, A.J.; Bellinato, D.F.; Peixoto, A.A.; Valle, D.; Lima, J.B.P. Effect of insecticide resistance on development, longevity and reproduction of field or laboratory selected Aedes aegypti populations. PLoS ONE 2012, 7, e31889. [CrossRef] 